\title{
Reduction of Salmonella Enteritidis in the Spleens of Hens by Bacterins That Vary in Fimbrial Protein SefD
}

\author{
Roxana Sanchez-Ingunza, Jean Guard, ${ }^{2}$ Cesar A. Morales, ${ }^{2}$ and Alan H. Icard ${ }^{3}$
}

\begin{abstract}
The objective of this research was to determine whether variation in the presence of fimbrial protein SefD would impact efficacy of bacterins as measured by recovery of Salmonella enterica serovar Enteritidis (Salmonella Enteritidis) from the spleens of hens. Two bacterins were prepared that varied in SefD content. Also, two adjuvants were tested, namely, water-in-oil and aluminum hydroxide gel (alum). Control groups for both adjuvant preparations included infected nonvaccinated hens and uninfected nonvaccinated hens. At 21 days postinfection, Salmonella Enteritidis was recovered from $69.7 \%, 53.1 \%$, and $86.0 \%$ from the spleens of all hens vaccinated with bacterins lacking SefD, bacterins that included SefD, and infected nonvaccinated control hens, respectively. No Salmonella was recovered from uninfected nonvaccinates. Results from individual trials showed that both bacterins reduced positive spleens, but that the one with SefD was more efficacious. Alum adjuvant had fewer side effects on hens and egg production as compared to water-in-oil. However, adjuvant did not change the relative recovery of Salmonella Enteritidis from spleens. These results suggest that SefD is a promising target antigen for improving the efficacy of immunotherapy in hens, and is intended to reduce Salmonella Enteritidis in the food supply.
\end{abstract}

\section{Introduction}

$S$ ALMONELLA ENTERICA SEROVAR ENTERITIDIS (Salmonella Enteritidis) accounts for nearly $20 \%$ of laboratoryconfirmed illnesses of salmonellosis in recent years (CDC, 2014). Consumption of shell eggs and egg products is associated with risk of infection from Salmonella Enteritidis in humans (CDC, 2003; Cowden et al., 1989; Elson et al., 2005). A large multistate outbreak of Salmonella Enteritidis led to a recall of approximately 500 million eggs. The experience reinforced the necessity of coordinating quality assurance programs with federal regulatory measures (FDA, 2009; CDC, 2011). Management practices that incorporate vaccination to impede introduction and re-emergence of pathogenic serotypes such as Salmonella Enteritidis on-farm can be important additions to quality assurance programs for reducing foodborne illness (Gast, 2007; FDA, 2014).

Vaccination of chickens to reduce Salmonella Enteritidis on-farm is not a mandatory requirement in the United States (FDA, 2014). Vaccination programs appear to partially protect chickens from infection or transmission of this pathogen through eggs (Vielitz et al., 1992; Gast et al., 1993; Nassar et al., 1994; Hassan and Curtiss, 1996, 1997; Lopes et al., 2006; Adriaensen et al., 2007). With a goal of improving vaccine efficacy in mind, whole genome comparisons were performed between phenotypic variants of Salmonella Enteritidis to find promising antigenic targets (Guard et al., 2011). The gene sefD, which is a critical component of the fimbria SEF14, was disrupted by deletion of a single nucleotide in the genome of a non-egg-contaminating strain. Fimbrial proteins are often promising vaccine candidates (Rajashekara et al., 2000).

Fimbria SEF14 is encoded by the sefABCD operon, and it is transcribed under regulation of the sefR gene (Clouthier et al., 1993; Edwards et al., 2000, 2001). The operon is restricted to Salmonella Enteritidis and other closely related Oantigen group D Salmonella. The production of SefD protein was shown to be temperature dependent (Morales et al., 2012). Others have shown SefD to be required for cell binding and macrophage internalization, which contributes to the survival of Salmonella Enteritidis in vivo (Edwards et al., 2000). Thus, expression of the fimbria may contribute to

${ }^{1}$ CEVA Biomune, Lenexa, Kansas.

${ }^{2}$ U.S. Department of Agriculture, Agricultural Research Service, Athens, Georgia.

${ }^{3}$ Grafton Scientific Staffing Companies, Leawood, Kansas.

(C) The Author(s) 2015; Published by Mary Ann Liebert, Inc. This Open Access article is distributed under the terms of the Creative Commons Attribution Noncommercial License (http://creativecommons.org/licenses/by-nc/4.0/) which permits any noncommercial use, distribution, and reproduction in any medium, provided the original author(s) and the source are credited. 
transfer of the pathogen from the environment to the oral mucosa of the chicken, after which it would be repressed at the body temperature (Morales et al., 2012). Because differences in phenotype and virulence associated with expression of SefD were evident, experiments were conducted to explore whether bacterins that varied in SefD content also varied in efficacy against Salmonella Enteritidis in laying hens. Two strains, namely, Salmonella Enteritidis sefD mutant 29108 ( $\Delta$ SefD 29108) and complemented mutant 100713 (SefD+ 100713) (Morales et al., 2012), were used to prepare bacterins. In addition, two adjuvants were used in formulating the vaccine to minimize side effects of vaccination.

\section{Materials and Methods}

\section{Bacterial strains}

Salmonella Enteritidis PT4 (22079) was the parent strain used to derive all mutants, and it was isolated from a poultry farm environment in California (Kinde et al., 1996). The strain was previously characterized as a weak biofilm former and shown to be capable of egg contamination (Guard et al., 2011). Strains 29108 and 100713 were derived from strain 22079 , and all steps in the construction of the mutant and its complement have been described (Morales et al., 2012). $\Delta$ SefD 29108 cannot produce SefD because it carries a nonpolar knockout mutation of sefD. SefD+ 100713 contains pCR2.1-TOPO with $F$ (lacZa'-sefD+) and it was confirmed to have constitutive transcription of sefD (Morales et al., 2012). Biofilm formation, which is a marker of phenotype and virulence characteristics, was confirmed as described (Guard et al., 2011).

\section{Description of hens and sample collection}

A total of 309 specific-pathogen-free White Leghorn hens were obtained from the same laboratory. Each treatment group initially contained 20 birds, and the number of hens tested per group is stated in Table 1 . Hens were kept in individual laying cages in a building with environmental monitors for light and temperature. Hens that showed signs of morbidity were euthanized and removed from the study without contributing data from culturing spleens. Water and feed were provided ad libitum. Hens were euthanized 21 days after challenge for sampling, which is a time associated postinfection with persistence in spleens but not oviducts (Guard et al., 2010). Spleens were aseptically removed and stored at $4^{\circ} \mathrm{C}$ until processed for isolation of Salmonella Enteritidis. Egg production was recorded from 14 days before the first immunization through 21 days after challenge. Mean daily egg production per treatment group per surviving hen was calculated for each group as described (Fialho et al., 2001). The length of time between vaccine doses varied between trials because flock egg production was allowed to rebound before potentially stressing hens with a second vaccination.

\section{Preparation of cells for use in bacterins}

$\Delta$ SefD 29108 and SefD+ 100713 were cultured from frozen stocks onto brilliant green (BG) agar (Acumedia, Neogen Corporation, Lansing, MI) at $37^{\circ} \mathrm{C}$ for $24 \mathrm{~h}$. One colonyforming unit (CFU) was transferred to $10 \mathrm{~mL}$ of $\mathrm{BHI}$ broth and incubated for $24 \mathrm{~h}$ at $37^{\circ} \mathrm{C}$ with shaking at $150 \mathrm{rpm}$ (In- nova 4000; New Brunswick Scientific, Enfield, CT). Two (2) $\mathrm{mL}$ of cell culture was transferred to $500 \mathrm{~mL}$ BHI broth in 1-L flasks, and a total of up to $2 \mathrm{~L}$ was prepared per strain. Media for SefD + 100713 was supplemented with $100 \mu \mathrm{g} / \mathrm{mL}$ ampicillin to maintain the plasmid. Cultures were incubated in water baths at $37^{\circ} \mathrm{C}$ for $24 \mathrm{~h}$ with shaking and then placed at $4^{\circ} \mathrm{C}$ for $2 \mathrm{~h}$. Cells were pelleted at $10,000 \times g$ for $10 \mathrm{~min}$ at $5^{\circ} \mathrm{C}$ (Sorvall RC 4B Plus centrifuge). Pellets were washed twice in $300 \mathrm{~mL}$ sterile phosphate-buffered saline (PBS) (10 mM phosphate, $138 \mathrm{mM} \mathrm{NaCl}, 2.7 \mathrm{mM} \mathrm{KCl}[\mathrm{pH} 7.4])$ and pelleted again. Pellet weights were recorded.

Batches of cultures were combined and suspended in $10 \mathrm{~mL}$ PBS, and viable cell counts were determined. Bacterins are vaccines prepared from inactivated cells prepared by adding a kill step. To kill cells, preparations contained in 50 -mL capped vials were submerged in a water bath at $60^{\circ} \mathrm{C}$ for $60 \mathrm{~min}$. Thimerosal was added to a final concentration of $0.01 \%$. To confirm that cells were killed, a $0.5-\mathrm{mL}$ volume of the final preparation was tested by cultivation onto $\mathrm{BG}$ and in BHI. Inactivated cells were kept at $-80^{\circ} \mathrm{C}$ until use. Methods describing other details of characterization, namely, determination of relative amounts of lipopolysaccharide (LPS) Oantigen, transmission electron microscopy (TEM), protein extraction and immunoblot analysis for presence of SefD, and tests for stability are described in Supplementary Data S1 (Supplementary Data are available online at www.liebertpub .com/fpd).

\section{Preparation of water-in-oil emulsified bacterins}

Cell suspensions, $4 \mathrm{~mL}$, were mixed in a PRO400 homogenizer (ProScientific Inc., Oxford, CT) at $8000 \mathrm{rpm}$ for $2.5 \mathrm{~min}$ with $16 \mathrm{~mL}$ of an oil mixture containing $80 \%$ (vol/ vol) Hexadecane (Sigma-Aldrich, St. Louis, MO), 10\% (vol/ vol) Span 80 (Sigma-Aldrich), 7\% (vol/vol) TWEEN 85 (Sigma-Aldrich), and 3\% (vol/vol) Span 85 (Sigma-Aldrich) following a published protocol for producing oil-emulsion bacterins (Gast et al., 1993).

\section{Adjustments to two batches of bacterins emulsified with a water-in-oil adjuvant}

One liter of 16-h culture was used to produce a total of $5 \mathrm{~mL}$ of inactivated suspensions for the first vaccine dose. For the second round of dosing, cells were grown $8 \mathrm{~h}$ longer to increase cell density. One liter of a 24-h culture was concentrated to $5 \mathrm{~mL}$ by centrifugation as described previously, and an additional 20\% (vol/vol) PBS was added. In the second set of hens used to evaluate the bacterins in water-in-oil adjuvant, $1 \mathrm{~L}$ of $24-\mathrm{h}$ culture was concentrated to a final volume of $10 \mathrm{~mL}$ and an additional $20 \%$ (vol/vol) in PBS was added to the first and second vaccine doses. These adjustments were necessary to achieve the appropriate number of doses for the number of hens included in trials.

\section{Details of vaccination of hens with bacterins in water-in-oil adjuvant}

Hens receiving water-in-oil bacterins were vaccinated as two trials. Hens in the first trial began vaccination at 25.4 weeks of age with bacterins delivered in $0.2-\mathrm{mL}$ volumes containing 3.3 or $3.7 \mathrm{mg}$ total protein, respectively, for preparations made from $\Delta$ SefD 29108 and SefD+ 100713. 


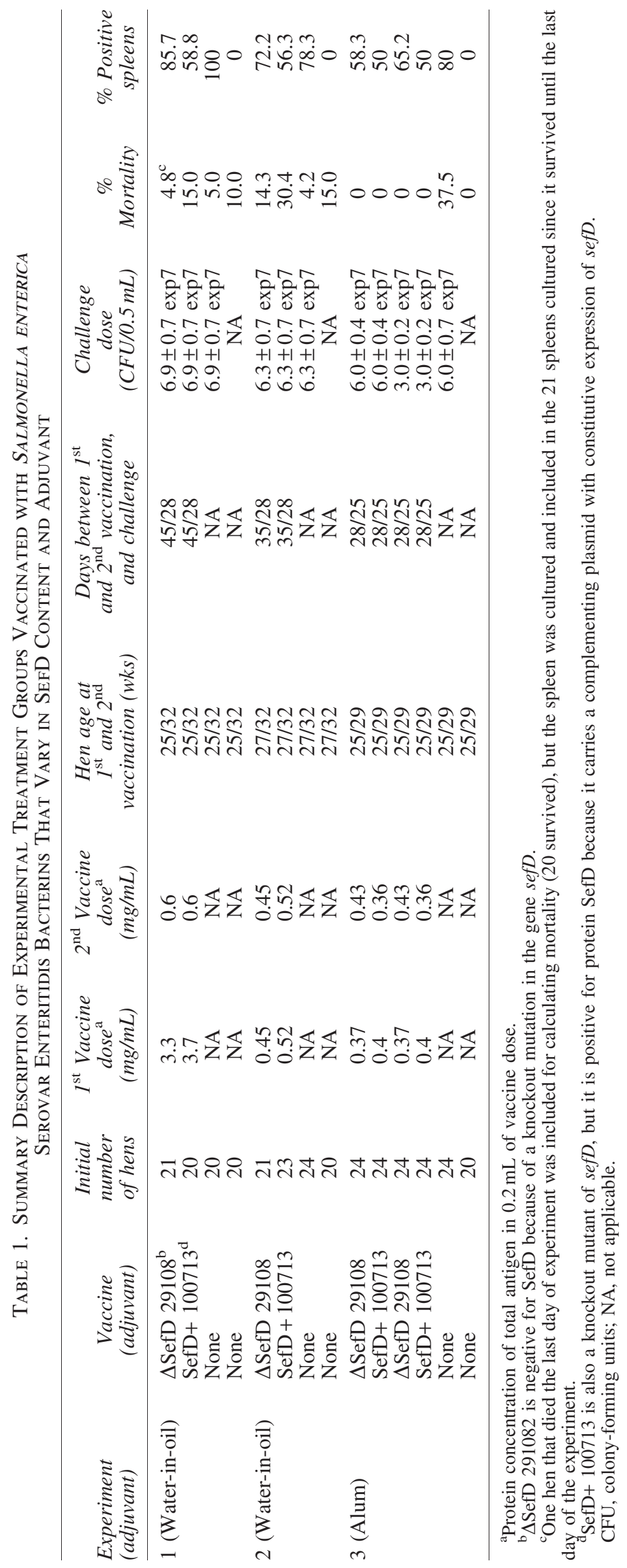


Vaccines were administered subcutaneously (SQ) in the neck. Six weeks later, hens at 31.7 weeks of age received a second immunization containing $0.60 \mathrm{mg}$ total protein in both bacterins in $0.2 \mathrm{~mL}$ for hens. Birds were challenged intramuscularly (IM) 4 weeks after the second immunization with $6.9 \pm 0.7 \times 10^{7} \mathrm{CFU}$ of parent strain 22079 in $0.5 \mathrm{~mL}$ of PBS. The second trial started vaccination at 26.7 weeks of age, again at 31.7 weeks of age, and then challenged was at 35.7 weeks of age. Bacterins $\Delta$ SefD 29108 and SefD+ 100713 had 0.47 and $0.52 \mathrm{mg}$ per hen in the first and second vaccine dose, respectively. The infectious dose 4 weeks after the second vaccination in the second trial was $6.3 \pm 0.7 \times 10^{7} \mathrm{CFU}$ of parent strain 22079 .

\section{Preparation of bacterins by emulsification in aluminium hydroxide gel (alum)}

Cells were prepared as described for water-in-oil bacterin. To emulsify cells with alum, suspensions were first homogenized in a Bullet Blender ${ }^{\circledR}$ (NextAdvance, Averill Park, NY) as indicated in the protocol for $E$. coli cultures (NextAdvance, 2013). Four (4) mL of the homogenized cell suspensions were mixed in a PowerGen 125 homogenizer (Fisher Scientific) at wheel scale 4 for $2.5-3.0 \mathrm{~min}$ with $16 \mathrm{~mL}$ of Alhydrogel ${ }^{\circledR}$ (Sergeant, Clifton, NJ).

\section{Details of vaccination of hens with alum}

Hens from the same flock were split into two separate rooms. Each set of hens was vaccinated SQ at 25 and $29 \mathrm{wks}$ with $0.2-\mathrm{mL}$ doses containing 0.37 or $0.40 \mathrm{mg}$ total protein from $\Delta$ SefD 29108 and SefD+ 100713 bacterins, respectively. Second vaccinations contained 0.43 or $0.36 \mathrm{mg}$ in 0.22 or $0.18 \mathrm{~mL}$, respectively. Four weeks after immunization, hens that were in one room were infected IM with $6.0 \pm 0.04 \times 10^{7}$ CFU of parent strain 22079 in $0.5 \mathrm{~mL}$ PBS. Hens in the second room received a challenge dose of $3.0 \pm 0.02 \times 10^{7} \mathrm{CFU}$. Both groups of hens, namely, those infected at $6.0 \times 10^{7}$ and $3.0 \times 10^{7}$ $\mathrm{CFU}$, shared the same control group of hens to reduce the use of animals in research.

\section{Cultivation of spleens for isolation of Salmonella Enteritidis}

Spleens were held at $4^{\circ} \mathrm{C}$ after collection and processed $24 \mathrm{~h}$ after collection. Each spleen was placed in $100-\mathrm{mL}$ sample bags with $10 \mathrm{~mL}$ of trypticase soy broth (Acumedia) and then pummeled for $1 \mathrm{~min}$ at high speed in a Stomacher ${ }^{\circledR}$ 80 Biomaster (Seward, Worthing, UK). Samples were incubated at $37^{\circ} \mathrm{C}$ for $48 \mathrm{~h}$ and a $100-\mu \mathrm{L}$ aliquot was streaked onto $\mathrm{BG}$ agar. Plates were incubated for $24 \mathrm{~h}$ at $37^{\circ} \mathrm{C}$ and identities of suspected colonies were biochemically determined by the Enterotube II method (Difco BD, Detroit, MI).

\section{Statistical analysis}

The number of eggs produced daily by each group of hens and the average O-antigen LPS antibody titers against Group D Salmonella was compared using the Student $t$-test. Mean daily egg production per hen per experimental group, adjusted for any hens removed from the study due to morbidity or premature mortality, was evaluated using a multivariate analysis of variance (SYSTAT v13.1; Systat Software, Inc., San Jose, CA). Raw data, comprised of negative and positive spleens per group, were analyzed by Fisher exact test for determination of probability values ( $p$-value).

\section{Results}

Variation of SefD correlated with changes in cell shape, colony morphology, and lipopolysaccharide O-antigen

Colony morphology of SefD+ 100713 varied from that of $\Delta$ SefD 29108 and parental strain 22079, and the latter two were similar to each other. Parent 22079 and $\Delta$ SefD 29108 had colonies with a wrinkled appearance previously associated with biofilm formation, whereas those from SefD+ 100713 had a smooth appearance, when grown on selective agar media (BG agar, Acumedia) (Fig. 1) (Guard et al., 2011). Growth characteristics also differed between strains. On average, the $\Delta$ SefD 29108 cell suspension had $3.93 \pm 1.2$ times more cells than that estimated for SefD+ 100713 per preparation, which was equivalent to $\mathrm{CFU} / \mathrm{mL}$ of $3.27 \times 10^{13}$ versus $0.83 \times 10^{13}$, respectively. However, pellet weights were very similar between strains (data not shown). Transmission electron microscopy showed that CFU counts differed because the length of SefD 100713 cells was up to 10 times greater than that of the $\Delta$ SefD 29108 cells (Fig. 2). Therefore, it appears that fewer but longer cells of SefD+ 100713 have similar pellet weights as compared to more numerous but shorter cells of $\Delta$ SefD 29108. Parental strain 22079 and mutant $\Delta$ SefD 29108 each produced similar amounts of LPS O-antigen binding sites, but more O-antigen than SefD+ $100713(p<0.001)$ (Supplementary Material S1). Overall, 22079 and 29108 had $2^{3}$ more O-antigen binding sites than did SefD+ 100713.

\section{SefD was detected in cell preparations made from SefD+ 100713}

Expression of SefD was confirmed for SefD+ 100713 by the observation of a strong signal that was not detectable in parental 22079 or $\Delta$ SefD 29108 when the peptide-generated labeled antibody was used for immunoblots (Fig. 3). This result agreed with previous results that transcription of sefD was present for SefD+ 100713 strain and absent in $\Delta$ SefD
FIG. 1. Colony morphology of Salmonella Enteritidis that varies in SefD. Contrast and brightness of images were adjusted $30 \%$ to make image suitable for publication. (A) Parental strain 22079 PT4, which has a complete sefD gene but is negative for transcription. (B) $\Delta$ SefD 29108, which has a knockout mutation of sefD. (C) SefD+ 100713, which constitutively expresses SefD from a plasmid.
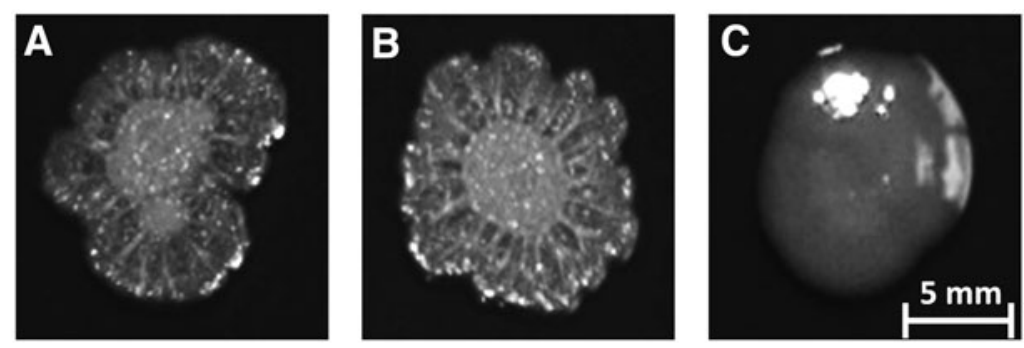

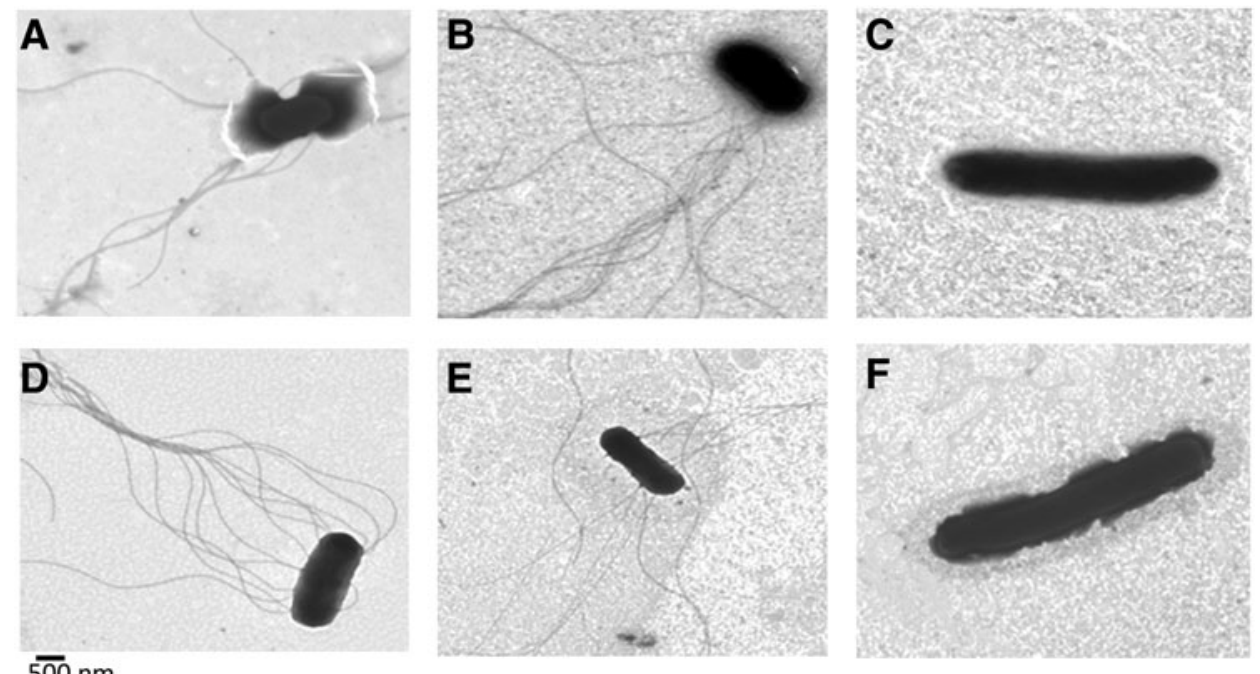

FIG. 2. Transmission electron microscopy micrographs of Salmonella Enteritidis. Bacteria were cultured in brain heart infusion broth for $24 \mathrm{~h} \mathrm{(A,} \mathrm{B,} \mathrm{C)} \mathrm{or} 16 \mathrm{~h} \mathrm{(D,} \mathrm{E,} \mathrm{F)} \mathrm{at} 37^{\circ} \mathrm{C}$. (A, D), Parental strain $22079 \mathrm{PT}$, which has a complete sefD but lacks transcription. (B, E), $\Delta$ SefD 29108, which has a knockout mutation of sefD. (C, F) SefD+100713, which constitutively expresses SefD from a plasmid.

29108 and parent 22079 (Guard et al., 2012). Agreement between results from transcription studies and immunologic analysis of cell surface properties is important because it strongly suggests the fimbria was assembled on the outer membrane. It has been reported that isolation of SefD is difficult (Clouthier et al., 1994). Immunoblot assay was also done using a commercial SEF14 antibody to provide some evidence of the SEF14 fimbria content of bacterins (Edwards et al., 2000). The SEF14 antibody used under nonreducing conditions detected a band of $\approx 14 \mathrm{kDa}$ in extracts from the parent, mutant, and complemented mutant (data not shown).

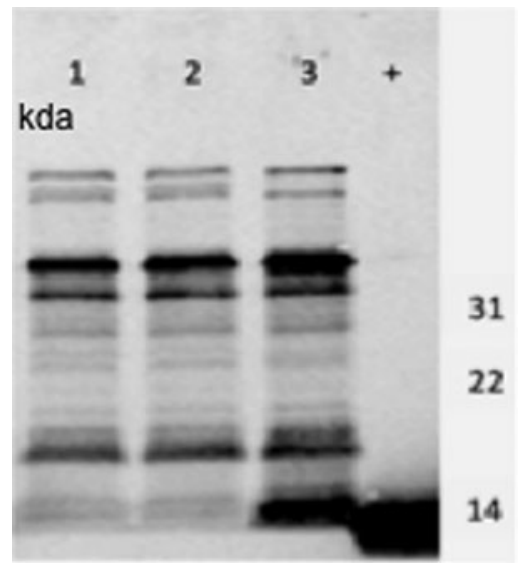

FIG. 3. Immunoblot assay of Salmonella Enteritidis strains used to produce bacterins that varied in SefD content. Lane 1: Parental 22079 , no sefD transcription at $37^{\circ} \mathrm{C}$ but does have the intact gene. Lane 2: $\Delta$ SefD 29108, which has a knockout mutation of sefD. Lane 3: SefD+ 100713, producing SefD constitutively by a plasmid containing sefD. Lane 4: SefD neutralizing peptide, which was included as a positive control.

\section{Salmonella Enteritidis was reduced in spleens by vaccination, but more so by SefD+100713}

Overall, 49 of 57 spleens $(86.0 \%)$ were positive at 21 days after challenge of unvaccinated hens (Table 1). For hens vaccinated with $\Delta$ SefD 29108 and then challenged, 60 of 86 spleens $(69.8 \%)$ were positive (Table 1$)$. For all hens vaccinated with SefD+ 100713 and challenged, 43 of 81 spleens $(53.1 \%)$ were positive (Table 1$)$. The range of positive spleens was between $50 \%$ and $60 \%$ for SefD+ 100713 and between $58.3 \%$ and $85.7 \%$ for $\Delta$ SefD 29108 . These results were consistent across four different sets of birds divided as two independent trials for hens with water-in-oil bacterins and one trial of hens vaccinated with alum preparations as a paired set. Bacterin $\Delta$ SefD 29108 reduced the number of positive spleens as compared to unvaccinated controls that were also infected ( $p=0.02$ one tail). Bacterin SefD +100713 also reduced the number of positive spleens as compared to unvaccinated controls $(p<0.0001$ one tail). In summary, results support that SefD+ 100713 performed better than did $\Delta$ SefD 29108 at reducing Salmonella Enteritidis in the spleens of hens under the experimental parameters described ( $p=0.02$ one tail). More details of statistical analyses presented in Table 1 are included in Supplementary Data S2.

\section{Adjuvant-associated side effects on egg production and mortality}

A 30-day moving average was applied to each group laying eggs daily (\% daily egg production) to minimize daily fluctuations from variables such as when eggs were collected or minor differences between flocks due to weather and age (Fig. 4). Trends in egg production for hens infected with Salmonella Enteritidis are somewhat predictable. For example, no significant differences in egg production were observed between any of the groups before vaccination with either water-in-oil or alum 
FIG. 4. Percent (\%) daily egg production for hens that vary in vaccination and challenge status for Salmonella Enteritidis. A 30-day moving average was applied as discussed in text (A and B). Challenge was at day 80 for hens receiving bacterin in water-in-oil (A) and at day 65 for hens immunized with the alum adjuvant bacterin (B). Egg production was similar between the two groups receiving water-in-oil bacterin (data not shown), so only the data from the second group is presented. Lines associated with treatment groups are as follows:

a. (-- ) Vaccinated with bacterin $\Delta$ SefD 29108 then infected with wild type (WT).

b. (---) Vaccinated with bacterin SefD+ 100713 then infected with WT.

c. (-:-:-) Not vaccinated, but infected with WT.

d. (—) Vaccinated with bacterin $\Delta$ SefD 29108, but not infected.

e. (-) Vaccinated with bacterin SefD+100713, but not infected.

f. (----) Not vaccinated and not infected.

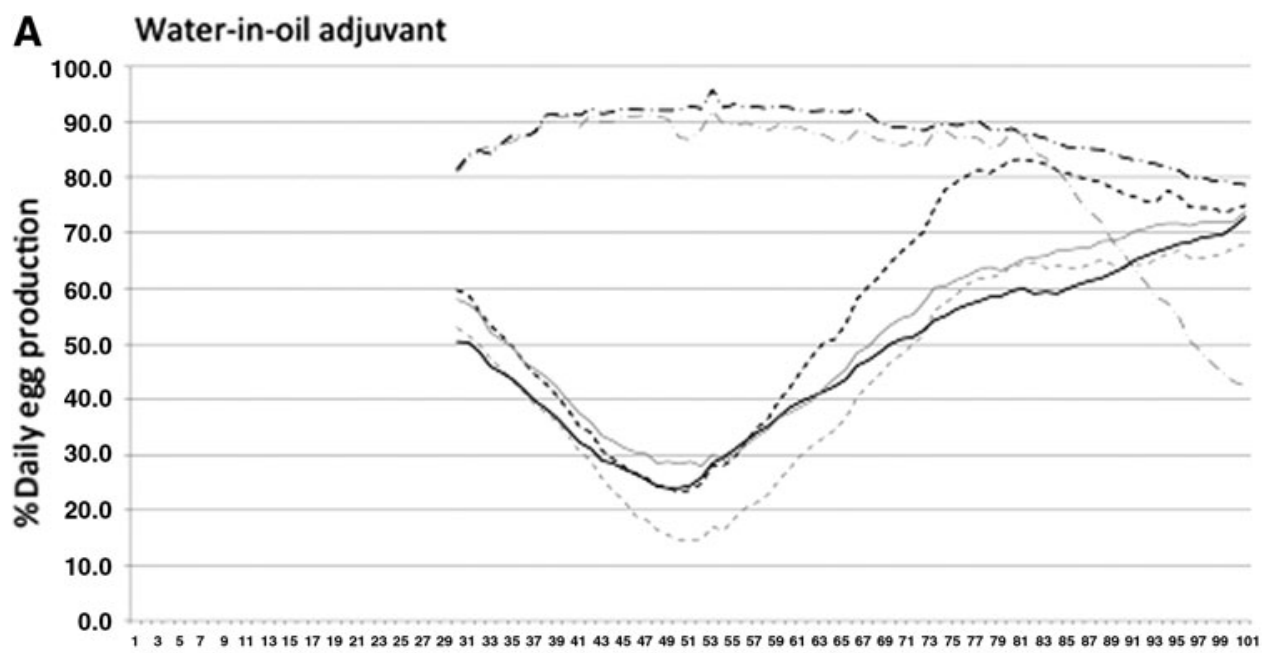

\section{B Aluminium hydroxide gel (alum) adjuvant}

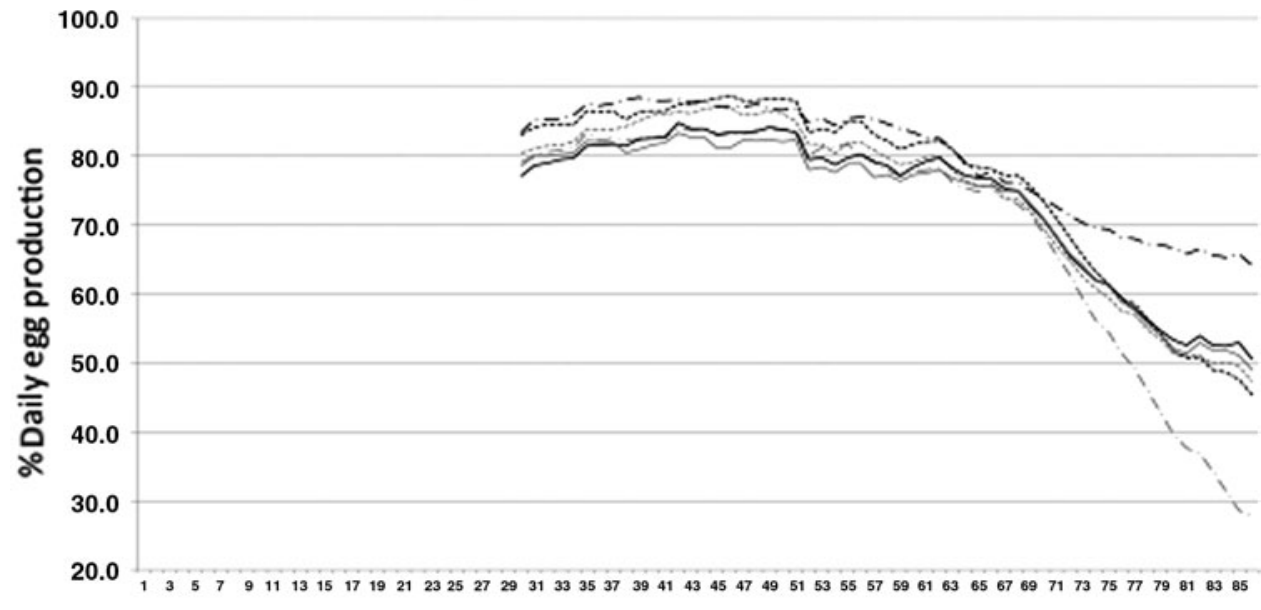

Day of experiment preparations $(p>0.05)$. An expected decline in egg production was observed for all treatment groups as hens passed peak production. It was also expected that egg production would drop $(p<0.01)$ in unvaccinated hens that were challenged (Fig. 4A and B, line c), and that it would remain highest for unvaccinated hens that were not challenged (Fig. 4A and B, line f).

Both groups of hens that were vaccinated with water-in-oil preparations experienced a similar $(p<0.01)$ decline in egg production. Results of egg production for the second test of the water-in-oil bacterin are shown (Fig. 4A, lines a, b, d, and e). In contrast, hens vaccinated with bacterins emulsified with alum showed no significant decline in egg production after vaccination (Fig. 4B, lines a, b, d, and e). Thus, adjuvant had a major impact on the response of the hen to vaccination as assayed by egg production. Additional repetition would help to assess further how changing to the alum adjuvant impacted performance of bacterins.

Mortality also differed between groups, and it was highest for hens receiving SefD+ 100713 prepared in water-in-oil adjuvant (Table 1). Mortality was two- to three-fold higher for SefD+ 100713 than it was for $\Delta$ SefD 29108. Changing adjuvant to alum may have helped to decrease mortality and impact on egg production following vaccination. However, calculations suggest that up to 4 deaths per 24 hens over 21 days is within 1 SD of average loss (Supplementary Data S2). Again, further analysis would be necessary to determine whether a change of adjuvant lowered mortality or whether observed mortality was within parameters expected for hens in production.

\section{Discussion}

The presence of the fimbrial protein SefD appeared to improve the efficacy of a bacterin for reducing Salmonella Enteritidis in the spleens of laying hens under these experimental conditions ( $p=0.02$ Fisher exact test). Constitutive expression of SefD had consequences for the bacterial cell, and efficacy increased with loss of O-antigen, loss of biofilm, and presence of SefD. Expression of sefD impacted morphological transitions that somewhat resemble the sessile and planktonic states exhibited by other pathogens (Moreno-Paz et al., 2010). Bacterins that are currently marketed probably lack SefD, because wild-type strains appear to be functional sefD mutants (Morales et al., 2012). It is common to find natural mutants of sefD. For example, point mutations present 
in sefD reference sequences of Salmonella Gallinarum, Salmonella Typhi, Salmonella Paratyphi A, and some field isolates of Salmonella Enteritidis occur at the same location within a penta-adenosine region of the open reading frame. Salmonella Enteritidis generates strain heterogeneity due to the accumulation of single nucleotide polymorphisms, and these experiments were conducted with a well-characterized and sequenced strain kept under selection pressure to grow to high cell density (Guard-Petter, 1998). It is possible that use of other strains could impact results.

Vaccination of egg-laying chickens is not mandated in the United States, but it facilitates comprehensive programs to reduce the risk of Salmonella Enteritidis entering the food supply (Gast, 2007; Pitesky et al., 2013). Products for vaccinating egg-laying chickens in the United States include genetically modified live vaccines of heterologous serotypes such as Salmonella Typhimurium (Hassan and Curtiss, 1997). These products would not contain sefD because the gene is known to be absent (McClelland et al., 2001). Vaccines made from killed cells of Salmonella Enteritidis could vary widely in SefD content because specific stimuli to initiate expression might be absent during production (Berghaus et al., 2011). In contrast, modified live vaccines that are made from related serovar group D1 serotypes would have the potential to express SefD (Matulova et al., 2012; Penha Filho et al., 2012; De Cort et al., 2013; Nandre et al., 2013).

\section{Conclusions}

Results presented here suggest that SefD is a specific antigen from Salmonella Enteritidis that should be explored for increasing efficacy of currently marketed vaccines. However, further experimentation is required to explore specifics of application, including addressing the most economical route of vaccination. Moreover, the adjuvant should be selected to avoid side effects in the hen.

\section{Acknowledgments}

Animal experiments were approved by the Southeast Poultry Research Laboratory Institutional Animal Care and Use Committee (NIH OLAW Assurance number A4298-01). Dr. Mary Pantin-Jackwood and Dr. Henry Stone, U.S. Department of Agriculture, Agricultural Research Service (USDA-ARS) in Athens, GA, provided valuable advice on histopathology and adjuvant formulation. Dr. Richard Gast, USDA, National Poultry Research Center, provided a review of this article. Dr. Zaid Abdo, USDA, ARS, provided independent statistical analysis of data. This research was funded by the U.S. Department of Agriculture, Agricultural Research Service (USDA-ARS), under ARS Project Number 6612-32000-007-00, Genetic Analysis of Poultry-Associated Salmonella enterica to Identify and Characterize Properties and Markers Associated with Egg-Borne Transmission of Illness.

\section{Disclosure Statement}

No competing financial interests exist.

\section{References}

Adriaensen C, De Greve H, Tian JQ, et al. A live Salmonella enterica serovar Enteritidis vaccine allows serological dif- ferentiation between vaccinated and infected animals. Infect Immun 2007;75:2461-2468.

Berghaus RD, Thayer SG, Maurer JJ, Hofacre CL. Effect of vaccinating breeder chickens with a killed Salmonella vaccine on Salmonella prevalences and loads in breeder and broiler chicken flocks. J Food Prot 2011;74:727-734.

[CDC] Centers for Disease Control and Prevention. Outbreaks of Salmonella serotype enteritidis infection associated with eating shell eggs-United States, 1999-2001. MMWR Morb Mortal Wkly Rep 2003;51:1149-1152.

CDC. Centers for Disease Control and Prevention. Vital signs: Incidence and trends of infection with pathogens transmitted commonly through food-Foodborne diseases active surveillance network. MMWR Morbid Mortal Wkly Rep 2011; 60:749-755.

CDC. Incidence and trends of infection with pathogens transmitted commonly through food-Foodborne diseases active surveillance network, 10 U.S. sites, 2006-2012. MMWR Morbid Mortal Wkly Rep 2014;63:328-332.

Clouthier SC, Collinson SK, Kay WW. Unique fimbriaelike structures encoded by sefD of the SEF14 fimbrial gene cluster of Salmonella enteritidis. Mol Microbiol 1994;12: 893-901.

Clouthier SC, Muller KH, Doran JL, Collinson SK, Kay WW. Characterization of three fimbrial genes, sefABC, of Salmonella enteritidis. J Bacteriol 1993;175:2523-2533.

Collinson SK, Emody L, Muller KH, Trust TJ, Kay WW. Purification and characterization of thin, aggregative fimbriae from Salmonella enteritidis. J Bacteriol 1991;173:47734781.

Cowden JM, Chisholm D, O’Mahony M, et al. Two outbreaks of Salmonella enteritidis phage type 4 infection associated with the consumption of fresh shell-egg products. Epidemiol Infect 1989;103:47-52.

De Cort W, Geeraerts S, Balan V, et al. A Salmonella Enteritidis hilAssrAfliG deletion mutant is a safe live vaccine strain that confers protection against colonization by Salmonella Enteritidis in broilers. Vaccine 2013;31:5104-5110.

Edwards RA, Matlock BC, Heffernan BJ, Maloy SR. Genomic analysis and growth-phase-dependent regulation of the SEF14 fimbriae of Salmonella enterica serovar Enteritidis. Microbiology 2001;147:2705-2715.

Edwards RA, Schifferli DM, Maloy SR. A role for Salmonella fimbriae in intraperitoneal infections. Proc Natl Acad Sci U S A 2000;97:1258-1262.

Elson R, Little CL, Mitchell RT. Salmonella and raw shell eggs: Results of a cross-sectional study of contamination rates and egg safety practices in the United Kingdom catering sector in 2003. J Food Prot 2005;68:256-264.

[FDA] U.S. Food and Drug Administration. Egg Safety Final Rule: Prevention of Salmonella Enteritidis in shell eggs during production, storage, and transportation. In: Federal Register, Volume 21 CFR Parts 16 and 118. Federal Register: Health and Human Services (HHS), 2009, pp. 33030-33101.

FDA. Production, storage, and transportation of shell eggs. In: 21CFR118. U.S. Food and Drug Administration (ed.). Silver Spring, MD: U.S. Department of Health \& Human Services, 2014, 27 pp.

Fialho F, Ledur M, Avila V. Mathematical model to compare egg production curves. Rev Bras Ciência Avícol 2001;3: 211-217.

Gast RK. Serotype-specific and serotype-independent strategies for preharvest control of food-borne Salmonella in poultry. Avian Dis 2007;51:817-828. 
Gast RK, Stone HD, Holt PS. Evaluation of the efficacy of oilemulsion bacterins for reducing fecal shedding of Salmonella enteritidis by laying hens. Avian Dis 1993;37:1085-1091.

Guard J, Gast RK, Guraya R. Colonization of avian reproductive-tract tissues by variant subpopulations of Salmonella enteritidis. Avian Dis 2010;54:857-861.

Guard J, Morales CA, Fedorka-Cray P, Gast RK. Single nucleotide polymorphisms that differentiate two subpopulations of Salmonella enteritidis within phage type. BMC Res Notes 2011;4:369.

Guard J, Sanchez-Ingunza R, Morales C, et al. Comparison of $d k g B$-linked intergenic sequence ribotyping to DNA microarray hybridization for assigning serotype to Salmonella enterica. FEMS Microbiol Lett 2012;337:61-72.

Guard-Petter J. Variants of smooth Salmonella enterica serovar Enteritidis that grow to higher cell density than the wild type are more virulent. Appl Environ Microbiol 1998;64:21662172.

Hassan JO, Curtiss R 3rd. Effect of vaccination of hens with an avirulent strain of Salmonella typhimurium on immunity of progeny challenged with wild-type Salmonella strains. Infect Immun 1996;64:938-944.

Hassan JO, Curtiss R 3rd. Efficacy of a live avirulent Salmonella typhimurium vaccine in preventing colonization and invasion of laying hens by Salmonella typhimurium and Salmonella enteritidis. Avian Dis 1997;41:783-791.

Kinde H, Read DH, Chin RP, et al. Salmonella enteritidis, phase type 4 infection in a commercial layer flock in southern California: Bacteriologic and epidemiologic findings. Avian Dis 1996;40:665-671.

Laemmli UK, Beguin F, Gujer-Kellenberger G. A factor preventing the major hard protein of bacteriophage $\mathrm{T} 4$ from random aggregation. J Mol Biol 1970;47:69-85.

Lopes VC, Velayudhan BT, Halvorson DA, Nagaraja KV. Preliminary evaluation of the use of the sefA fimbrial gene to elicit immune response against Salmonella enterica serotype Enteritidis in chickens. Avian Dis 2006;50:185-190.

Matulova M, Havlickova H, Sisak F, Rychlik I. Vaccination of chickens with Salmonella Pathogenicity Island (SPI) 1 and SPI2 defective mutants of Salmonella enterica serovar Enteritidis. Vaccine 2012;30:2090-2097.

McClelland M, Sanderson KE, Spieth J, et al. Complete genome sequence of Salmonella enterica serovar Typhimurium LT2. Nature 2001;413:852-856.

Miles AP, Saul A. Extraction and characterization of vaccine antigens from water-in-oil adjuvant formulations. In: Therapeutic Proteins: Methods and Protocols. Smales CM and James DC (eds.). New York: Humana Press, 2005, pp. 293-300.

Morales CA, Guard J, Sanchez-Ingunza R, Shah DH, Harrison M. Virulence and metabolic characteristics of Salmonella enterica serovar Enteritidis strains with different sefD variants in hens. Appl Environ Microbiol 2012;78:6405-6412.

Moreno-Paz M, Gomez MJ, Arcas A, Parro V. Environmental transcriptome analysis reveals physiological differences between biofilm and planktonic modes of life of the iron oxidizing bacteria Leptospirillum spp. in their natural microbial community. BMC Genomics 2010;11:404.

Nandre RM, Chaudhari AA, Matsuda K, Lee JH. Immunogenicity of a Salmonella Enteritidis mutant as vaccine candidate and its protective efficacy against salmonellosis in chickens. Vet Immunol Immunopathol 2013;144:299-311.

Nassar TJ, al-Nakhli HM, al-Ogaily ZH. Use of live and inactivated Salmonella enteritidis phage type 4 vaccines to immunise laying hens against experimental infection. Rev Sci Tech 1994;13:855-867.

NextAdvance. Protocol for E. coli Cultures Homogenization in the Bullet Blender ${ }^{\circledR}$. Available at: http://nextadvance.com/ public/file/protocols/Bullet_Blender_Homogenizer_Protocol_ Homogenization_E_Coli.pdf: NextAddvance, 2013, accessed July 7, 2013.

Penha Filho RA, Moura BS, de Almeida AM, Montassier HJ, Barrow PA, Berchieri Junior A. Humoral and cellular immune response generated by different vaccine programs before and after Salmonella Enteritidis challenge in chickens. Vaccine 2012;30:7637-7643.

Pitesky M, Charlton B, Bland M, Rolfe D. Surveillance of Salmonella enteritidis in layer houses: A retrospective comparison of the Food and Drug Administration's egg safety rule (2010-2011) and the California Egg Quality Assurance Program (2007-2011). Avian Dis 2013;57:51-56.

Rajashekara G, Munir S, Alexeyev MF, Halvorson DA, Wells CL, Nagaraja KV. Pathogenic role of SEF14, SEF17, and SEF21 fimbriae in Salmonella enterica serovar Enteritidis infection of chickens. Appl Environ Microbiol 2000;66: 1759-1763.

Vielitz E, Conrad C, Voss M, Lohren U, Bachmeier J, Hahn I. Immunizing against Salmonella infections with live and inactivated vaccines. Dtsch Tierarztl Wochenschr 1992;99: 483-485. (In German.)
Address correspondence to:
Jean Guard, DVM, PhD
U.S. Department of Agriculture
Agricultural Research Service
950 College Station Road
Athens, GA 30605

E-mail: jean.guard@ars.usda.gov 